\title{
A inserção do Saliente Nordestino na economia global e sua importância geoestratégica na defesa nacional: o caso do Choke Point de Natal
}

\section{Edu Silvestre de Albuquerque}

\section{Introdução}

Apesar das reformas do canal interoceânico do Panamá, os volumes transportados e as novas classes de navios cargueiros e petroleiros recoloca em cena as velhas rotas marítimas da época dos descobrimentos e reforça a importância das linhas de comunicação sul-atlânticas.

Ao mesmo tempo, a continua descoberta de novos campos de gás e sal em águas territoriais e as possibilidades de extensão da zona econômica marítima ampliam as necessidade de defesa de nosso mar territorial. E pari passu, nas últimas décadas, o corpo diplomático brasileiro tem trabalhado com a ideia de transformação da Bacia Sul-Atlântica numa zona de cooperação e paz, resultando na criação da ZOPACAS, ainda que sem dispor dos vetores (modernização das marinhas da região) e instalações necessárias (estruturas administrativas e operacionais de segurança e defesa unificadas).

Nesse sentido, é fundamental que a comunidade acadêmica contribua com os debates sobre a incorporação de meios e sua distribuição espacial para a obtenção de uma estratégia eficiente de segurança de nosso mar territorial e das rotas de comércio sul-atlânticas.

A porção mais oriental do território sulamericano é usualmente indicada nas aulas de geografia como evidência da teoria da deriva das placas tectônicas, uma vez que sua forma de saliente se "encaixa" na concavidade do Golfo da Guiné, já na costa ocidental africana. Essa é razão pela qual a Região Nordeste do Brasil é geopoliticamente chamada de Promontório Nordestino; e que corresponde ao Saliente Nordestino na conceituação empregada nas forças armadas brasileiras.

Desse contexto geográfico mais amplo, destacamos no presente estudo a posição estratégica da cidade de Natal, que apresenta quatro fases ao longo da história onde se percebe nitidamente a permanência dessa vantagem de posição. O primeiro momento data do final do séc. XVI, quando a Fortaleza dos Reis Magos edificada na barra do Rio Grande (Potengi), representa maior segurança ao avanço lusitano para o Oeste do continente, bem como o reforço da segurança

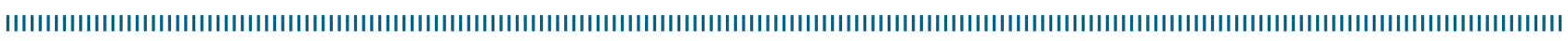
Como citar este artigo:

ALBUQUERQUE, Edu Silvestre de. "A inserção do Saliente Nordestino na economia global e sua importância geoestratégica na defesa nacional: o caso do Choke Point de Natal”. In: RÜCKERT, A. A.; SILVA, A. C. P. da; SILVA, G. de V. (Orgs.). Geografia Política, Geopolítica e Gestão do Território: integração sul-americana e regiões periféricas. Porto Alegre: Editora Letra1, 2018, p. 357-365 DOI 10.21507/9788563800367-23 
marítima no combate aos corsários. O segundo momento engloba as primeiras décadas do séc. XX, quando a aviação comercial transatlântica insere Natal nas rotas internacionais, praticando a amerissagem nas águas do Potengi ${ }^{1}$. O terceiro momento é registrado com a instalação da base norte-americana durante a II Guerra Mundial, a maior base daquele país no exterior, servindo de apoio logístico para as operações aliadas no Norte da África e na Europa. Finalmente, o momento atual é representado pela ampliação física e de missões da Base Aérea de Natal no escopo da nova estratégia de defesa do espaço aéreo brasileiro.

A primeira dimensão analisada no presente texto diz respeito à inserção geoeconômica global do Promontório Nordestino, destacando-se a configuração das redes de comunicação (doravante tratadas como vetor de transportes) na articulação da vastas áreas continentais sul-americanas com a costa brasileira no Atlântico Equatorial e Atlântico Sul. Como se trata de uma área muito ampla ${ }^{2}$, nos deteremos apenas nos dados comerciais do estado do Rio Grande do Norte, que acreditamos extrapoláveis ao conjunto nordestino e nacional ${ }^{3}$.

A segunda dimensão explorada neste texto remete ao papel do Saliente Nordestino para a organização da defesa nacional e para a segurança do tráfego nas águas atlânticas, onde analisaremos mais detidamente os casos da Base Aérea de Natal $(B A N T)^{4}$ e da Base Naval de Natal, que fazem desta

| |I||||||||||||||||||||||||||||||||||

1 Dentre essas empresas tivemos: a francesa Lignes Aeriennes Latecoère (depois substituída pela Compagnie Generale Aeropostale e, posteriormente, pela Air France; a alemã Condor (depois Lufthansa); a britânica British Airways; a italiana Ala Littoria (Linee Aeree Transcontinentali Italiane); e a norte-americana Pan Am (Panair do Brasil).

2 A Região Nordeste é uma das cinco unidades administrativas adotadas pelo Instituto Brasileiro de Geografia e Estatística (IBGE), e apresenta uma área de $1.554 \mathrm{mil} \mathrm{km}^{2}$, que equivale a algo superior ao conjunto dos países da Europa Ocidental.

3 Agradeço à pesquisadora Naiara Jaciane Ribeiro dos Santos, à época bolsista de pesquisa da UFRN, pela coleta e tratamento dos dados estatísticos sobre comércio exterior, utilizando o Sistema Alice (MDIC) e o programa GvSig, respectivamente. Contato: naiara_ribeiro1990@hotmail.com

4 A base aérea de Natal localiza-se em verdade no município de Parnamirim, mas este apresenta-se totalmente conurbado à capital e integrante de sua área metropolitana. cidade o mais importante choke point brasileiro ${ }^{5}$.

Se formos capazes de aprender as importantes lições ensinadas pela geohistória ${ }^{6}$, então o papel estratégico do Promontório Nordestino continua importante no presente e para o futuro, seja para a projeção das estruturas logísticas necessárias ao comércio exterior, seja para a organização da defesa do Estado brasileiro.

\section{A inserção geoeconômica global do Promontório Nordestino}

Nos anos 1950 e 60, a geógrafa Therezinha de Castro destacava costumeiramente em suas publicações e palestras os eventos geohistóricos mais importantes na demonstração da vantagem da posição estratégica de determinados territórios na guerra e na paz. Para esta renomada geopolítica, a projeção atlântica era, ao lado da continentalidade, um condicionante geográfico da mais alta importância para a realização dos objetivos econômicos e políticos brasileiros.

Por certo, as vantagens estratégicas de posição continuam manifestas na atual "economia internacional liberal estável”. (GILPIN, 2004). As trocas mercantis globalizadas dependem ainda mais intrinsecamente do modal marítimo, onde mesmo um país continental como o Brasil realiza cerca de $95 \%$ de seu comércio exterior pelo mar, tornando sua rica produção das áreas interiores

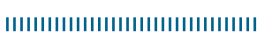

5 Choke points ou Chokepoint é um termo da estratégia militar para determinadas formas geográficas como um vale (em terra) ou estreito (no mar), em que uma força armada é forçada a passar. Por ser um ponto de estrangulamento pode permitir que uma força defensora numericamente inferior possa impedir a progressão da força adversária.

6 Essa tradição de resgate da geohistória para a construção de justificativas geopolíticas é impulsionada no ocidente pelo britânico Halford John Mackinder, desde a famosa conferência intitulada The geographical pivot of history, de 25 de janeiro de 1904, ministrada na tradicional Royal Geographical Society. Para H. Mackinder haveria uma rivalidade irreconciliável entre o poder marítimo e o poder terrestre. As guerras greco-pérsicas na Antiguidade, que defrontaram o poder naval grego e o poder terrestre persa, e a Guerra dos Sete Anos na Idade Moderna, decorrente da disputa por possessões coloniais na América e Oriente entre a potência naval inglesa e a potência terrestre francesa, foram episódios históricos estudados por Mackinder. 
cada vez mais dependente da estrutura portuária da costa atlântica. ${ }^{7}$

Estudo do Ministério do Desenvolvimento, Indústria e Comércio Exterior (MDIC) sobre a inserção brasileira nos fluxos internacionais, aponta que os produtos manufaturados representaram $55,1 \%$ do total das vendas externas brasileiras em 2005, e o setor do agronegócio outros $37 \%$. Contudo, a maioria desses produtos industrializados se liga fortemente ao próprio agronegócio e ao setor extrativista mineral, indicando a força de nossas vantagens comparativas.

Por certo existem diferenças regionais importantes, sobretudo quando analisados estados como Rio de Janeiro e São Paulo; mas também temos economias regionais periféricas como a potiguar, onde esse quadro de dependência das vantagens comparativas é mesmo ampliado: "Segundo informações da Secretaria Estadual de Agricultura (SAPE, 2004), as atividades do agronegócio são responsáveis por mais de $70 \%$ de tudo que o Rio Grande do Norte exporta, e dos treze principais produtos comercializados no exterior dez são oriundos do agronegócio." (NUNES et al., 2006, p. 6).

A cesta de produtos das exportações do estado envolve produtos tradicionais como açúcar e castanha do caju, e novos produtos como camarão em cativeiro e frutas tropicais (Quadro 1) ${ }^{8}$. E quando ocorrem exportações de manufaturados, usualmente são de produtos fortemente dependentes de recursos naturais, como vestuário de malha.

Em termos de mercados de destino das exportações potiguares, em 2005-2006 cerca de $70 \%$ das vendas foram para os blocos União Europeia e Nafta (SILVA e MONTÁLVAN, 2008),

IIIIIIIIIIIIIIIIIIIIIIIIIIIIIIIIII

$7 \mathrm{E}$ em que pese a imperiosa necessidade de constantes serviços de dragagem para vencer a pouca profundidade de nosso portos.

8 Dos 20 mil ha da área de fruticultura no estado, cerca de $90 \%$ se concentra no Polo Assu-Mossoró (Vale do Açu e Baraúna), suficiente para elevar o RN à condição de segundo maior exportador brasileiro neste segmento, destacando a produção de melão, mamão, banana, manga, melancia e abacaxi. Silva e Montálvan (2008) observam que a carcinicultura e a fruticultura irrigada geraram $54 \%$ das exportações potiguares em 2006.
Quadro 1. Estrutura das exportações totais do Rio Grande do Norte por grupos de produtos - 1996, 2001 e 2006 (em \%)

\begin{tabular}{lccc}
\hline Capítulos & $\mathbf{1 9 9 6}$ & $\mathbf{2 0 0 1}$ & $\mathbf{2 0 0 6}$ \\
\hline Peixes, crustáceos & 5,45 & 22,92 & 16,04 \\
Frutas & 41,90 & 29,66 & 38,89 \\
Gorduras & 2,65 & 2,27 & 0,42 \\
Açucares & 25,42 & 14,27 & 12,04 \\
Sal & 2,44 & 5,75 & 3,61 \\
Combustíveis & 0,00 & 0,00 & 7,52 \\
Algodão & 4,05 & 2,63 & 2,66 \\
Vestuário de malha & 0,00 & 16,66 & 2,01 \\
Outros produtos & 18,01 & 5,84 & 16,81 \\
\hline Total & $\mathbf{1 0 0 , 0 0}$ & $\mathbf{1 0 0 , 0 0}$ & $\mathbf{1 0 0 , 0 0}$ \\
\hline
\end{tabular}

Fonte: Adaptado de SILVA e MONTÁLVAN, 2008.

ambos localizados na Bacia do Atlântico.

A importância da União Europeia (UE) e do NAFTA continua alta para as vendas potiguares, algo próximo dos $40 \%$ e dos $30 \%$, respectivamente (Tabelas 1 e 2). Ainda por questão de proximidade geográfica, o mercado do Caribe absorveu quase a totalidade das exportações estaduais de óleos brutos de petróleo no biênio 2010-2011; enquanto a Venezuela absorveu expressivas cotas de açúcar produzidas no estado no mesmo período.

Nessa dinâmica atlântica do comércio exterior se insere ainda a África, apesar da grande oscilação em 2011 (2,35\% das vendas potiguares) quando comparado a 2010 (6,5\%), e o Mercosul, que também caiu para $6,93 \%$ contra os $9,26 \%$ verificados no ano anterior.

A concentração geográfica das exportações do RN nos mercados atlânticos é tão significativa, que mesmo a China, importante mercado de destino das exportações brasileiras, representou apenas $0,59 \%$ e $2,71 \%$ das exportações potiguares no biênio 2010-2011.

Essa influência atlântica nas exportações potiguares é demonstrada em seus principais mercados de destino em 2010: Europa Ocidental, América do Norte, Argentina, Venezuela e Nigéria. O ano de 2011 repete o mesmo padrão, basicamente com o acréscimo da China à lista. Uma espécie de segundo nível de importância é representado justamente pelos BRICS, com a China alçada à condição de mercado comprador de primeiro nível em 2011. 
Tabela 1. Balança Comercial do Rio Grande do Norte - 2010

\begin{tabular}{lrrrr}
\hline BLOCOS ECONÔMICOS & EXP.(US\$ FOB) & \% & IMP. (US\$ FOB) & \% \\
\hline ÁFRICA SUBSAARIANA & 18.204 .530 & 6,42 & 3.031 .548 & 0,94 \\
ÁFRICA & 18.367 .766 & 6,47 & 6.588 .094 & 2,06 \\
ALADI & 50.089 .498 & 17,66 & 44.656 .388 & 13,98 \\
ALADI (EXCETO MERCOSUL) & 23.829 .828 & 8,4 & 6.921 .807 & 2,16 \\
BRIC & 3.479 .107 & 1,22 & 155.966 .949 & 48,83 \\
CARIBE & 307.078 & 0,1 & & \\
CARICOM & & & & \\
ECOWAS & 15.924 .193 & 5,61 & & \\
MERCOSUL & 26.259 .670 & 9,26 & 37.734 .581 & 11,81 \\
NAFTA & 90.939 .619 & 32,07 & 44.356 .999 & 13,88 \\
UNIÃO EUROPÉIA & $113.342 .32039,98$ & & 56.125 .438 & 17,57 \\
SADC & 2.131 .777 & 0,75 & 3.031 .548 & 0,94 \\
TOTAL GERAL & $\mathbf{2 8 3 . 4 9 1 . 4 8 7}$ & & $\mathbf{3 1 9 . 3 9 5 . 2 4 2}$ & \\
\hline
\end{tabular}

Fonte: Sistema Alice, Ministério do Desenvolvimento, Indústria e Comércio Exterior (MDIC), 2011.

Tabela 2. Balança Comercial do Rio Grande do Norte - 2011

\begin{tabular}{lrrrr}
\hline BLOCOS ECONÔMICOS & EXP.(US\$ FOB) & $\mathbf{~ \% ~}$ & IMP. (US\$ FOB) & \% \\
\hline ÁFRICA SUBSAARIANA & 6.609 .414 & 2,35 & 972.582 & 0,4 \\
ÁFRICA & 6.609 .414 & 2,35 & 9.855 .858 & 4,06 \\
ALADI & 26.677 .332 & 9,48 & 57.562 .169 & 23,72 \\
ALADI (EXCETO MERCOSUL) & 7.175 .277 & 2,55 & 7.792 .788 & 3,21 \\
BRIC & 10.059 .439 & 3,57 & 43.272 .654 & 17,83 \\
CARIBE & 286.764 & 0,1 & 156.015 & 0,06 \\
CARICOM & 171.767 & 0,06 & & \\
ECOWAS & 4.795 .121 & 1,7 & 775 & 0 \\
MERCOSUL & 19.502 .055 & 6,93 & 49.769 .831 & 20,51 \\
NAFTA & 85.269 .689 & 30,32 & 41.222 .597 & 16,99 \\
UNIÃO EUROPÉIA & 112.839 .307 & 40,13 & 51.761 .540 & 21,33 \\
SADC & 482.429 & 0,17 & 971.807 & 0,4 \\
TOTAL GERAL & $\mathbf{2 8 1 . 1 8 1 . 3 3 4}$ & & $\mathbf{2 4 2 . 5 9 7 . 4 1 8}$ & \\
\hline
\end{tabular}

Fonte: Sistema Alice, Ministério do Desenvolvimento, Indústria e Comércio Exterior (MDIC), 2011.

Nas importações estaduais ${ }^{9}$, UE e NAFTA permaneceram mercados de destaque em 2010 e 2011, mas agora somados não passaram de $31,4 \%$ e $38,3 \%$ das compras externas em cada ano. Por sua vez, o Mercosul apresentou maior expressão ao saltar de 11,8\% em 2010 para 20,5\%

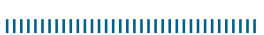

9 A composição das importações potiguares em 2006 destaca o setor da indústria com $92,77 \%$ do total, e o primário com apenas $7,23 \%$. Nos produtos industrializados destacam-se máquinas, equipamentos e peças para os setores têxtil e petrolífero, e produtos químicos e outros insumos para a indústria e a agricultura. (SILVA e MONTÁLVAN, 2008). em 2011. E indicando essa melhor distribuição espacial das importações, destaca-se ainda os BRIC com quase 49\% do mercado em 2010 (alavancado pela Índia) e 17,8\% em 2011 (alavancado pela China). Essa variação geográfica sinaliza, portanto, importantes fluxos de comércio também para o Atlântico Sul (Mercosul) e mercados asiáticos.

Dentre os mais importantes mercados nas compras externas potiguares de 2010 e 2011, destacam-se países da Europa Ocidental e América do Norte, bem como China, Índia, Egito e Argentina, confirmando a menor concentração 
nos mercados de origem quando comparados aos mercados de destino do comércio exterior potiguar.

Em suma, nem mesmo o desenvolvimento da cadeia industrial do petróleo e gás natural parece suficiente para alterar essa concentração das atividades econômicas e do setor externo potiguar no segmento agroextrativista, que se realiza na abundância de certos recursos naturais e na vantagem de localização do estado em face aos ricos mercados da Bacia do Atlântico Norte.

A vantagem de localização se reveste aqui na redução de custos de frete, um fator de competitividade diante de outras regiões produtoras mais afastadas ${ }^{10}$. Entretanto, essa mesma vantagem de localização parece contrabalançada pela forma excêntrica da projeção do território potiguar para leste e pela extensão de seu semiárido (ainda insuficientemente dotado de recursos hídricos canalizados).

Essas desvantagens geográficas associadas a diminuta participação potiguar nas importações (apenas $0,14 \%$ em 2006) e nas exportações nacionais (apenas $0,27 \%$ ), explicam sua exclusão de importantes projetos de vertebração do território nacional. Assim, a integração do heartland brasileiro com os portos atlânticos estará se fazendo por redes ferroviárias que não cruzam o território do Rio Grande do Norte, casos da Ferrovia Norte-Sul e da Nova Transnordestina (Figura 1).

Mas se esse relativo isolamento decorrente da excentricidade de sua forma geográfica alongada trouxe prejuízos ao estado na atual política de organização das redes de comunicação do país, na dimensão geopolítica essa característica geográfica pode reafirmar, outra vez, sua importância geohistórica.

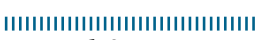

10 As diferenças que observamos entre a configuração espacial dos mercados de origem e de destino do comércio exterior potiguar podem indicar que os fretes de retorno acabam não sendo utilizados em sua plena potencialidade, hipótese que ainda carece de maior investigação. Este fato seria particularmente verificável no caso dos BRICS, em destaque nos mercados de origem e não nos mercados de destino do comércio exterior do RN.
Figura 1. Traçado da Ferrovia Transnordestina (Pecém/CE - Suape/PE).

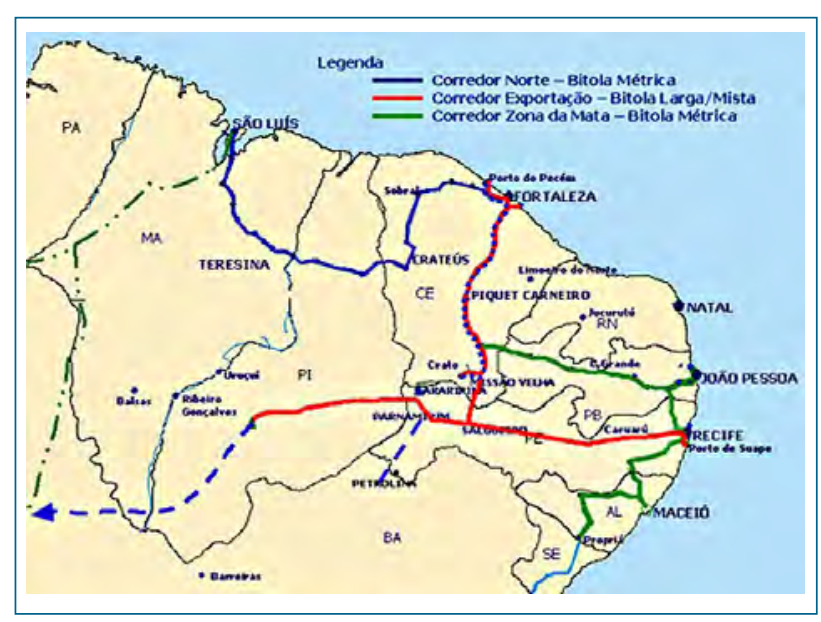

Fonte: WIKIPÉDIA. Disponível em <https://commons. wikimedia.org/wiki/File:Transnordestina136435.jpg>

\section{O valor geoestratégico do Saliente Nordestino}

O geopolítico prussiano Friedrich Ratzel percebeu que os territórios também apresentam um "valor político" advindo de sua posição geográfica e características físicas (extensão, forma, clima, relevo, etc.). Assim, por exemplo, uma determinada forma territorial pode sinalizar a escolha de uma dada configuração física das comunicações do país e não outra, bem como projetar suas possibilidades de inserção externa.

Mas para Ratzel o Estado em crescimento deve também manifestar uma política ativa, esforçandose pela delimitação de posições politicamente valiosas, caso das aquisições e possessões de ilhas e áreas costeiras para organizar a logística e proteção militar das rotas marítimas. (MORAES, 1990).

As teses lançadas por F. Ratzel são comprovadas pelos eventos históricos. O geopolítico Eli Alves Penha destaca que a primeira estratégia marítima efetivamente global foi aplicada pelo Infante Don Henrique no primeiro quartel do século $\mathrm{XV}$, quando "Portugal daria início às grandes expedições exploratórias, cuja meta era constituir uma rota oceânica das especiarias, como alternativa à rota terrestre então dominada pelos 
turcos otomanos, considerados hostis aos interesses comerciais europeus". (PENHA, 2011, p. 25). Para a realização desse empreendimento, os portugueses estabeleceram uma série de postos comerciais e militares nas faixas litorâneas das Américas, África e Ásia, representando a primeira rede comercial efetivamente globalizada da história mundial ${ }^{11}$.

No campo militar, a estratégia portuguesa depois de uma fase expansiva global ${ }^{12}$, concentrou esforços no Atlântico Sul com o apoio logístico de um cordão de ilhas estrategicamente situadas ao longo do Atlântico: os arquipélagos dos Açores, da Madeira e de Cabo Verde e as ilhas de Tristão da Cunha, Ascensão e Santa Helena ${ }^{13}$.

Posteriormente, essas três últimas ilhas viriam a se tornar peças chaves na estratégia militar britânica para o Atlântico ${ }^{\mathbf{1 4}}$. Essa importância global do Atlântico Sul se evidenciou na Batalha do Atlântico, quando Ascensão e Santa Helena foram utilizadas para ataques aliados contra os $U$-boats alemães ${ }^{15}$. Nesse mesmo período, Natal

| IIIIIIIIIIIIIIIIIIIIIIIIIIIIIIIIII

11 Evidente que outros elementos tiveram igual importância, seja de ordem educacional (formação de escolas de navegadores), militar (constituição de uma marinha costeira para proteger estuários e costas das incursões dos mouros magrebinos) ou tecnológica (inovações como caravelas e galeras para cobrir as grandes distâncias até as Índias).

12 Essa onipresença do poder marítimo lusitano se evidenciou na decisiva batalha naval de Diu (1509) pela conquista da Índia, e nos primeiros grandes desembarques anfíbios da história quando da conquista dos Estreitos de Ormuz e Málaca. Com o controle de Málaca e do comércio na junção do Golfo de Bengala e o Mar da China, Portugal vai cravar uma importante base em Cantão, representando a tentativa de subjugação do Império do Meio (China). Essa onipresença mundial portuguesa era ainda completada pelo controle de Ceuta - a chave para o Mediterrâneo -, do Cabo da Boa Esperança - passagem obrigatória no Caminho das Índias -, e do Estreito de Magalhães - passagem marítima do Atlântico ao Pacífico. O século XVII assinala a inflexão da política marítima portuguesa, com sua expulsão pelos holandeses das bases de Java, Sumatra e Málaca. (PENHA, 2011).

13 Muito antes de Ratzel, o jurista e eclesiástico português Frade Serafim de Freitas, na obra De Justo Império Lusitanorum Asiático, de 1625 , defende a apropriação de encraves costeiros para consolidar o comércio marítimo português na Ásia. (PENHA, 2011).

14 Necessitando de ajuda externa na guerra contra a Espanha (1660-1668), Portugal acaba por ceder ao Império Britânico grande parte de seus choke points marítimos, o que na prática já vinha ocorrendo em razão do enfraquecimento militar lusitano por conta do citado conflito.

15 As patrulhas marítimas dos aliados se intensificaram durante a II Guerra Mundial. Mas a guerra antisubmarino (Anti
(Parnamirim Field) recebe a maior base aérea norte-americana fora dos EUA, servindo de apoio logístico no desafio de cruzar o Atlântico para posicionar as tropas aliadas no norte africano e na Europa.

Após a II Guerra Mundial, parecia que haveria uma perda da importância do Atlântico Sul para a segurança global. De fato, nos mapas mackinderianos de início do século XX, a América dos Sul já era reconhecida como um continente demasiado distante da area core do Grande Jogo que envolve a Eurásia e os mares subjacentes. E a própria distribuição das bases americanas na atualidade corrobora que sua estratégia está voltada fundamentalmente para a Eurásia

Assim, durante a Guerra Fria. a doutrina de contenção formulada por $G$. Kennan centrou os esforços ocidentais no isolamento da União Soviética, situada justamente na área pivô da imensa massa continental eurasiana. Curiosamente, o geopolítico brasileiro Gen. Golbery do Couto e Silva (1967) viu na estratégia da U.S. Navy uma oportunidade para capacitar a Marinha brasileira no policiamento do Atlântico Sul. A estratégia contida no pensamento geopolítico golberyano e da própria Escola Superior de Guerra, preconizou pela especialização da Marinha na guerra antisubmarina atlântica e na proteção às rotas comerciais do Atlântico Sul, consideradas estratégicas para o petróleo que o Ocidente importava do Oriente Médio ${ }^{16}$.

Mas o acordo de defesa hemisférica (Tratado Interamericano de Assistência Recíproca - TIAR, de 1947) que assegura aos sul-americanos a

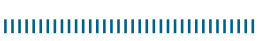

Submarine Warfare - ASW) é que se mostrou fundamental para a Batalha do Atlântico. Se em 1942, cerca de 1.600 navios aliados foram afundados por causa dos U-boats germânicos, no ano seguinte, as aeronaves americanas de longo alcance baseadas em terra e equipadas com radares infligiram pesadas perdas aos submarinos alemães, estimadas em $60 \%$ dos $U$-boats localizados no Mediterrâneo e no Atlântico (ROSA, 2014).

16 Para Cavagnari (1999) a orientação geopolítica brasileira no meio governamental é ainda derivada da "margem estratégica de tolerância" permitida pelos Estados Unidos, onde a própria industrialização parcial e tardia brasileira reflete a dependência das inversões de capitais e tecnologias externas (por muitos ainda entendida como uma dádiva da posição de aliado regional preferencial dos Estados Unidos). 
proteção militar estadunidense em caso de agressão extracontinental demonstraria toda a sua limitação para os interesses das nações sulamericanas no episódio da Guerra das Malvinas (1982). Durante esse conflito, os EUA prestaram maior importância ao aliado britânico, de modo que o satélite OTAN 3 permaneceu disponível à Grã-Bretanha para interceptar comunicações ${ }^{17}$, e os satélites estadunidenses $\mathrm{KH}-9$ (Big Bird), equipado com uma câmera fotográfica de resolução de 15 cm, e KH-11 n. 4, que orbitava sobre o Teatro de Operações diariamente, foram usados também no esforço de guerra britânico ${ }^{18}$.

Esse conflito nos evidenciou que não existe automatismo ou transferência de objetivos geoestratégicos mesmo entre nações aliadas, como se poderia subentender a partir do pensamento golberyano. A Guerra da Lagosta, ainda nos anos 1960, foi outro desses episódios onde embarcações da esquadra naval brasileira foram chamada à garantir a soberania sobre a Plataforma Continental (Decreto n. 28840/50), então constantemente ameaçada por embarcações de pesca francesas na altura do litoral nordestino.

\section{Considerações finais}

A geopolítica Therezinha de Castro também destacava em suas publicações e palestras a importância do Atlântico Sul como área pivô da defesa ocidental, com o Brasil ocupando uma posição estratégica entre as passagens caribenhas e austrais, relembrando o papel do saliente nordestino em defrontação com o litoral ocidental africano. Em verdade, não se trata de uma área de estreitamento tão pronunciado se comparado a outros importantes choke points, mas ainda assim os $2.900 \mathrm{~km}$ que separa ali os

IIIIIIIIIIIIIIIIIIIIIIIIIIIIIIIIII

17 Para áreas marítimas menores ou estrangulamentos efetivamente pouco extensos é possível utilizar os veículos aéreos não-tripulados (VANTs), tanto em missões de vigilância quanto de interdição, uma vez que podem ser colocados em qualquer situação de risco (ROSA, 2014). Os VANTs podem ainda ser utilizados a partir de navios, ampliando o raio de vigilância destes.

18 E especula-se que o satélite NOSS 3, operado pela United States Navy, tivesse sensores que possibilitaram à frota inglesa localizar submarinos argentinos.
Figura 2. O estreitamento atlântico entre Natal (Brasil)Dakar (Senegal).

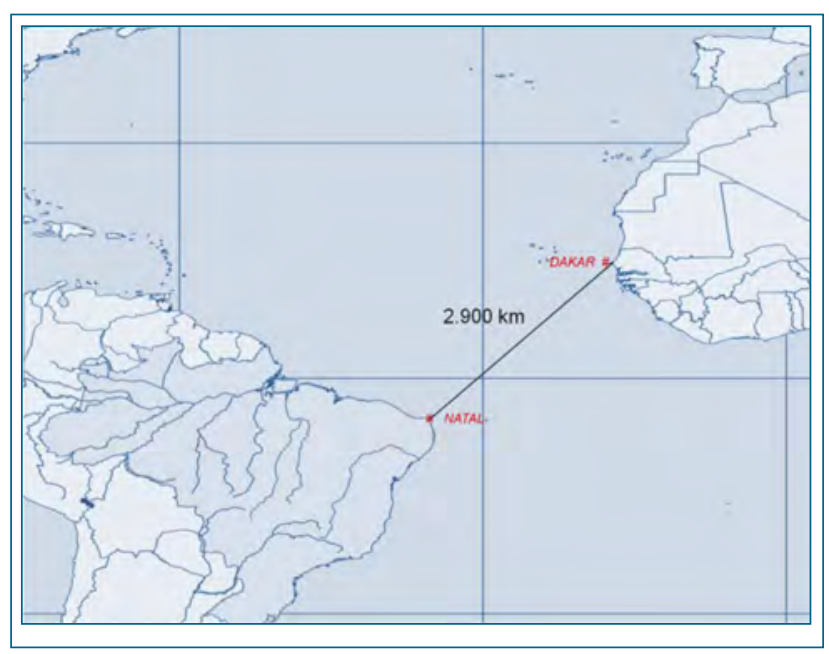

Fonte: Elaborado pelo autor.

dois continentes (Figura 2) representa quase que metade da distância dos demais "estreitamentos" sul-atlânticos.

A Guerra das Malvinas fez a Inglaterra perceber a importância estratégica de seu cordão de bases insulares no Atlântico Sul, reforçadas orçamentariamente mesmo diante da política neoliberal de Margareth Tatcher (Figura 3). A crescente importância das rotas interoceâncias com a globalização fez recentemente os Estados Unidos anunciarem a retomada de estudos para a reativação da IV Frota (descomissionada desde o fim da II Guerra Mundial). Também a França, que já mantêm importante base militar e cerca de 1.200 militares estacionados no Senegal, anunciou planos de ampliar sua presença na África Atlântica ${ }^{19}$.

Se a extensão da área de trafegabilidade dos navios mercantes dificulta a pronta resposta da cobertura naval, os sensores remotos instalados em plataformas espaciais e o reabastecimento em vôo tornam a interdição do espaço marítimo pelo poder aéreo algo cada vez mais factível. Todavia, isto não significa o desaparecimento da

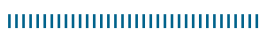

19 Disponível em <http://www.panapress.com/Franca-querreorganizar-presenca-militar-em-\%C3\%81frica--3-425940-47lang3-index.html>. Acesso em: 29 de Novembro de 2016. Na África Atlântica, a França mantêm instalações e tropas militares também no Gabão e na Costa do Marfim, e ainda deseja instalar uma base no Mali. 
Figura 3. Presença militar dos países da OTAN nos mares do sul.

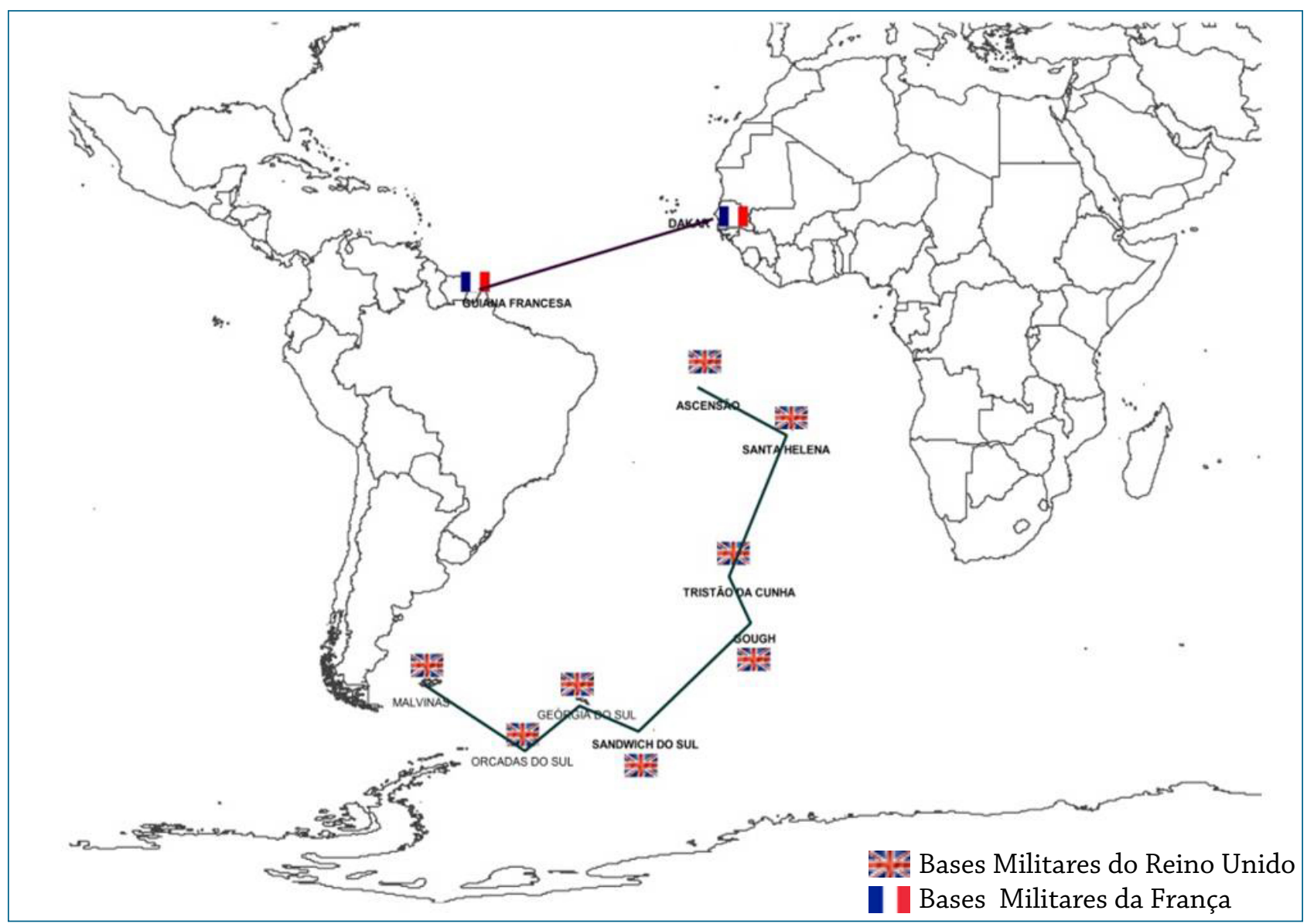

Fonte: Elaborado pelo autor.

importância dos choke points, e sim a adição de novas funções estratégicas. O reabastecimento em vôo, por exemplo, não inviabilizou o uso de bases militares em ilhas oceânicas na guerra moderna; ao contrário, a base de Diego Garcia, encravada no meio do índico, foi um dos aeródromos utilizados pela coalizão liderada pelos EUA na Guerra do Golfo. (ROSA, 2014).

Entretanto, a vantagem estratégica de Natal na porção oriental nordestina precisa ser relativizada no caso do poder marítimo, em razão da pouca profundidade do Rio Potengi, permitindo a ancoragem apenas de embarcações de baixo calado e limitando as movimentações simultâneas de embarcações na base naval de Natal. Outros portos no Saliente Nordestino poderiam cumprir melhor essa missão, sem as mesmas limitações físicas de operação.

Isso não significa que não possam ser mantidas e ampliadas certas funções na base naval de Natal que tenham por meios os navios-patrulhas, próprios para a realização das missões de busca e salvamento, de suporte logístico às ilhas oceânicas e de vigilância marítima na zona costeira, que é basicamente o que já vem sendo feito a partir daquelas instalações.

Já quanto ao poder aéreo, essa projeção extremo oriental de Natal pode representar importante ganho de tempo para a realização de missões militares e operações de busca e salvamento na imensidão do Atlântico Equatorial e do Atlântico Sul, que podem mesmo compensar o maior desgaste das aeronaves em decorrência da alta salinidade do ar. Vale discutir mais profundamente em algum momento se a BANT deva continuar com as missões de treinamento para pilotos de caça ou se reorientada para funções integradas à Marinha no escopo de segurança das águas territoriais e de busca e salvamento no Atlântico. 
A inserção do Saliente Nordestino na economia global e sua importância

geoestratégica na defesa nacional: o caso do Choke Point de Natal

\section{Referências}

ALBUQUERQUE, Edu Silvestre de. Uma breve história da Geopolítica. Rio de Janeiro: CENEGRI, 2011.

CAVAGNARI, Geraldo Lesbat. Brasil: a dimensão estrtégica da potência regional. In Carta Internacional, São Paulo, Funag/USP, n. 80, out. de 1999.

GILPIN, Robert. O desafio do capitalismo global. Rio de Janeiro: Record, 2004.

MACKINDER, Halford. The geographical pivot of history. The Geographical Journal, London, n. 4, v. 23, p. 421-444, april 1904.
PENHA, Eli Alves. Relações Brasil - África e geopolítica do Atlântico Sul. Salvador: EDUFBA, 2011.

RATZEL, Friedrich. O povo e seu território. In MORAES, Antonio C. Robert. Ratzel. São Paulo: Ática, 1990.

ROSA, Carlos Eduardo Valle. Poder Aéreo: guia de estudos. Rio de Janeiro: Luzes, 2014.

SILVA, J.; MONTÁLVAN, D. Exportações do Rio Grande do Norte: estrutura, vantagens comparativas e comércio intra-industrial. In $R E R$, Piracicaba, v. 46, n. 2, pp. 547568, abr./jun. 2008.

SILVA, Golbery do Couto e. Geopolítica do Brasil. Rio de Janeiro: José Olympio, 1967.

\section{Edu Silvestre de Albuquerque}

Graduação em Geografia (UFRGS); Especialização em Integração Econômica e Mercosul (UFRGS); Mestrado em Geografia (USP) e Doutorado em Geografia (UFSC). Docente dos Cursos de Geografia e do Programa de PósGraduação e Pesquisa em Geografia da Universidade Federal do Rio Grande do Norte (UFRN). Editor-Gerente da Revista de Geopolítica. Temas de pesquisa: Geopolítica e Relações Internacionais; Economia Distributista. E-mail: edusilvestre@ufrnet.br 